\title{
Anti-inflammatory, immunomodulatory agents as potential strategies against COVID-19: A systematic review
}

\author{
Reza Sinaei ${ }^{1}$, Sara Pezeshki ${ }^{2}$, Roya Sinaei ${ }^{2}$, and Ali Sinaei ${ }^{2}$ \\ ${ }^{1}$ Affiliation not available \\ ${ }^{2}$ Kerman University of Medical Sciences
}

June 17, 2020

\begin{abstract}
Aim: SARS-COV-2 infections are causing substantial morbidity and mortality, especially due to "exuberant cytokine storm". In this study we review effectiveness of anti-inflammatory and immunomodulatory drugs in this situation. Methods: Ovid MEDLINE, PUBMED, Google Scholar and Cochrane library searched for anti-inflammatory and immunomodulatory drugs against COVID-19 including: Anti malaria agents, non-steroidal anti-inflammatory drugs, steroids, cyclosporine, thalidomide, IVIG, interlukin-6 blockade, IL-1 blockade, tumor necrosis factor- $\alpha$ blockade, and Janus kinase inhibitors. Results: We included 95 studies. Unlike preliminary positive results, the effect of Chloroquine is questionable. Thalidomide has been shown to be effective in some studies but not be proved yet. Low dose Corticosteroids may be effective in the early phases of SARS-CoV-2 as a bridge. There is neither evidence of benefits or adverse outcomes for the use of NSAIDs, nor is there evidence indicating that target therapies (IL-1, TNF $\alpha$ and JAK inhibitors) and also cyclosporine are effective. In some cases and clinical trials, interlukin- 6 blockade is useful in critically ill patients. Finally, the high dose IVIG reversed the deterioration of patients in most clinical trials. Conclusion: Unlike preliminary positive results, Hydroxychloroquine seems ineffective. Thalidomide is effective in some cases. Although, low dose CS may be effective in the early phases of illness, administration of NSAIDs and steroids is controversial. The effectiveness of more target therapies including IL-1, TNF- $\alpha$, and JAK inhibitors, also cyclosporine is less clear. Tocilizumab can be used in severe situations, where other drugs are ineffective. IVIG can be used at least as a bridge therapy in deteriorating patients.
\end{abstract}

\section{Introduction}

The emergence of the novel coronavirus (nCoV-2), which causes severe respiratory infections, has become a global health concern [1]. About $80 \%$ of patients' experience mild to moderate disease and fatality rate is about $2.3 \%$ [2]. As disease progressed, a series of complications tend to develop, it is important to consider both the severity of disease and response capacity of health systems in the management strategies. At this setting, also for decision to hospitalization, bacterial colonization and secondary bacterial infections should be considered [3-5]. Given the rapid spread of COVID-19 and high mortality of severe disease, understanding the disease immunopathogenesis and inflammatory response is obligatory. According to the evidence, the SARS-COV-2 enter cells via receptor mediated (probably ACE2) endocytosis [6]. After recognition of virus by TLRs, signaling pathways activate NF-kB and then pro-inflammatory cytokines. The initiation of immune response is through some cytokines like IL-1 $\beta$ and $\mathrm{TNF} \alpha[7,8]$. Recently, structure analysis of the spike protein of $\mathrm{CoV}-2$ showed that this protein binds weaker to the ACE2 receptor on human cells [9], so probably several mechanisms are involving in pathogenesis, both environmental and cell entry. A cytokine profile like hemophagocytic lymphohistiocytosis (sHLH) is associated with COVID-19 severity [10]. Hyper inflammatory state including elevated IL-6 and ferritin are predictors of fatality [11].

Due to complexity of pathogenesis, as of this time, there is no effective antiviral treatment, so several potential rheumatic drugs as anti-inflammatory and immunomodulatory agents are candidates [12, 13]. 
Although, there have been no significant relapses of rheumatic disease in SARS-CoV-2 infection [14], the relation between them and vial infectious is very complex and even, a simple scenario of fever and arthritis may be challenging to differentiate between infectious and reactive arthritis $[13,15]$. These relatively low relapses, along with the historical background of using the rheumatic drugs in infectious diseases [12], justifies the hypothesis of their use in COVID-19.

This review focuses on the effects of some proposed rheumatologic drugs as their anti-inflammatory and immunomodulatory effects while ignoring or paying attention to some of their immunosuppressive effects.

\section{Methods}

\section{Study Design}

We aimed to include all scientific papers without limitations, which evaluated the anti-inflammatory, immunomodulatory agents against COVID-19. We excluded public health agencies or institutes recommendations because their frequent renewal. The PRISMA guideline was followed for study design, search protocol, screening and reporting.

Search strategy

A systematic review carried out with searching OVID MEDLINES, PUBMED, Google Scholar and Cochrane library databases from inception up to April 8, 2020 and updated on April 12, 2020. No language and status (abstract or full text) limitation were imposed. The following terms used in titles, abstracts and keywords: "COVID-19", "SARS-CoV-2", "Coronavirus", "2019-nCoV infection", "2019-nCoV disease", "2019 novel coronavirus disease", "MERS-CoV", "SARS-CoV", "severe acute respiratory syndrome", and "anti-inflammatory agents", "immunomodulatory agents", "antiviral agents", "cytokine storm", "inflammatory state", "drugs", "treatment", "Antimalarial", "Chloroquine (CQ)", "Hydroxychloroquine (HCQ)", "NSAIDs", "Glucocorticoids", "Thalidomide", "Cyclosporine A", "TNF $\alpha$ blocker (inhibitors)", "Tocilizumab", "interlukin-6 (IL-6) blocker", "Janus kinase (JAK) inhibitor", "anakinra", "IL-1 blocker", "cyclosporine", "IVIG".

Appraisal of the selected articles

Two authors and one high experienced librarian, extract articles independently, by providing information on the efficacy and safety of anti-inflammatory and immunomodulatory drugs in COVID-19. The first step consisted in the screening of titles and abstracts of all retrieved references and then proceeded to cross check the results. Due to rarity, we increased the references with using an additive snowballing technique. So additional relevant articles were identified.

\section{Results}

The initial search identified 521 results among total 1389 sources, of which a total of 95 relevant articles deemed suitable were included for 10 drug groups separately including, CQ and HCQ (21), NSAIDs (9), Corticosteroids (20), Thalidomide (7), IVIG (8), Cyclosporine (7), IL-6 blockers (11), IL-1 blocker (4), JAKinhibitors (4), and TNF blockers (4). In addition, 14 recommendations including one national guideline recommendations alongside expert consensus were included. We excluded public health agencies or institutes recommendations because their frequent renewal. We did not enter ongoing clinical trials and systematic reviews.

\section{Antimalarial agents (CQ and HCQ):}

Both immunomodulatory agents have been used in auto-inflammatory and Rheumatic diseases (e.g. Lupus, RA). They inhibit chemotaxis, nitric oxide production and phagocytosis. Also, may antagonize the action of prostaglandins (PGs), interfere with production of IL-6, IL-1, INF $\gamma$ and $\mathrm{TNF} \alpha$, and has antagonistic effects upon TLR7/9 [16, 17].

Studies: In vitro studies have suggested that CQ inhibits replication of MERS and SARS-CoV [18, 19]. Moreover, two studies revealed that these broad spectrum effects occur by both increasing endosomal $\mathrm{PH}$ 
and blocking replication; also, interfering with glycosylation of ACE-2 receptors of SARS-CoV [19, 20]. Moreover, the effects of CQ has been found during post entry stages via inhibition of viraPLpro [21].

One study revealed that $\mathrm{QC}$ can inhibit $\mathrm{nCoV}-2$ replication with a half maximal effective concentration (EC50) of $1.13 \mu \mathrm{M}$ and a half cytotoxic concentration (CC50) greater than $100 \mu \mathrm{M}$ [22]. Liu et al., found a similar CC50 for two drugs, but EC50 was more for HCQ than CQ [23]; Also, Yao et al., found that HCQ $(\mathrm{EC} 50=0.72 \mu \mathrm{M})$ is more potent than CQ $(\mathrm{EC} 50=5.4 \mu \mathrm{M})$ for virus inhibition [24]. Gao and colleagues revealed a significant improvement in the course of COVID-19 pneumonia and images focus of more than 100 patients with using CQ [25]. Another cohort of 62 patients revealed similar results with additional using of HCQ (400 mg/d for 5-days) [26]. An open-label non randomized controlled trial showed that HCQ (600 $\mathrm{mg} / \mathrm{d}$ for 10 days) reduces viral load in most COVID-19 patients specially in combination with azithromycin [27]. There are several issues with this study, including small sample size, lack of randomization, no qRTPCR data and drop out of multiple HCQ treated patients who clinically deteriorated. In a cohort of 30 patients while one group were given HCQ $400 \mathrm{mg}$ per day for 5 days and the other group were given only conventional treatment; no significant differ were found in clinical end points [28]. Sahraei and colleagues suggested that HQ is preferred due to less adverse effects and availability [29]. In contrast, in a recent cohort of 63 hospitalized CoV-2 patients, HCQ was associated with an increase need for escalation of respiratory support [30]. Also, a prospective study of 11 hospitalized patients reported no benefits from using HCQ and azithromycin [31]. In a parallel, double blind, randomized trial, high dose CQ (600 mg BID for 10 days, or a total dose $2.7 \mathrm{~g}$ ) was with higher QT prolongation and fatality than low dose (450 $\mathrm{mg}$ BID stat and then daily for 5 days). Overall fatality had no difference with similar non treated patients [32].

Some has suggested that CQ can administered with a dose of $500 \mathrm{mg}$ twice a day for 7-10 days [33, 34], additionally, it can administer for prophylactic effects [35-37]. Also, HCQ can administer at a dose of 400 mg BID stat, then $200 \mathrm{mg}$ BID [24], or with an alternative dose of $600 \mathrm{mg}$ daily in another recommendation [38].

Dong et al, also recommended like the national health commission of China (NHC) that published on March 3, 20. It suggested to treat patients with CQP (500 mg BID, first and then daily) for 3-7 days [39, 40]. Nicastry et al. published similar recommendation with HCQ $400 \mathrm{mg}$ (or CQ $500 \mathrm{mg}$ ) daily in combination with antivirals [41].

All previous studies have some limitations.

Although in a new cohort, HCQ was associated with an increased risk for escalation of respiratory support; the use of $\mathrm{CQ}$ and HCQ should be adhere to MEURI frame work. For ethical reasons and due to first results, alongside scatter experiences, the authors suggest using these drugs as therapeutic agents and even for prophylaxis especially in health workers.

\section{Systemic corticosteroids (CS) :}

CS reduce inflammation by inhibition of arachiodonic acid, IL1, TNF $\alpha$ and NF-kB. Their effects on immune system mediated mainly via $\mathrm{T}$ cells [16].

Studies: No in vitro studies were found on cytopathic effects of them alone against SARS-COV. Early studies have shown that inhibition of inflammation improved the outcomes in animal models infected with, SARS and MERS [42, 43]. Some other previous studies have shown that CS for treatment of SARS and MERS CoVs were associated with prolonged viremia and worse outcomes [44-46]. In another study, in the CoV infected pigs, prolonged administration of dexamethasone enhanced viral replication [47]. In a 2019 meta-analysis of CS using in SARS patients, four studies indicated harm effects including diabetes, psychosis, Avascular necrosis (AVN) and prolonged viremia [45, 48-50]. A review of patients with SARS of any cases revealed that, insufficient evidence exists to recommend the use of CS [51]. High dose CS in early stage of SARS-CoV had beneficial effects in two cohorts $[52,53]$. In a retrospective cohort of patients with SARS- CoV and sepsis, CS in 147 of 249 noncritical patients, reduced mortality and duration of admission, whereas 121 of 152 critical patients received CS and 25 patients died [54]. 
In this regard, a Cochrane review revealed an overall association between CS using and increased mortality in influenza patients, although the association among patients with CoVs was unclear [55].

In contrast, at least in two studies, CS were associated with lower duration of admission in COVID-19 patients $[56,57]$. Wong Y et al., reported 46 patients with COVID-19 that reduced their symptoms and chest CTscan results with 5 to 7 days methylprednisolone [58]. Also, in a retrospective cohort of 201 COVID-19 patients, CS was associated with lower mortality rate [59]. Zhou and colleagues, reported that moderate dose CS plus Intravenous Immunoglobulin (IVIG) significantly reduced lung injury [60]. Contrariwise, one study with a total 416 COVID-19 patients revealed that CS increased the mortality rate and appeared to be useful only in the cases with lymphopenia [61]. Although, CS have been used in combination therapies in three other case studies of 278 patients with COVID-19, their effects and adverse effects remain unclear [3, $62,63]$. In a case series of 24 COVID-19 patients, three patients with asthma who had received CS before admission; represented with severe symptoms requiring mechanical ventilation [64].

In another cohort, as a preprint yet, 11 of 31 COVID-19 patients who received CS within 24h of admission, had more complains and radiological abnormalities, that revealed CS was related to the presence of more symptoms at early presentation [65]. In contrast, analyzing of 89 existing MERS, SARS-CoV and SARSCoV2 suggested that CS may be beneficial in the early acute phase of infection [66]. Nevertheless, clinical use of CS for SARS-CoV2 pneumonia with the interaction of regulatory cytokine production and avoiding lung injury should be avoided [67,68], and may stimulate the hypothalamic axis, drive lymphopenia and promote the inflammatory responses [69].

Zheng et al., described a couple that treated with methylprednisolone and IVIG in addition to antiviral drugs successfully [70]. Also, Chen et al., reported a 45 years old woman who treated with Thalidomide and methyl prednisolone [71].

In two guidelines that published on March, 2020 for critically ill patients, in adult receiving mechanical ventilation who do not have ARDS, routine use of CS is suggested against (weak recommendation, LQE). In those have ARDS, use of CS is suggested (weak recommendation, LQE) [72, 73]. Also, NHC ( $7^{\text {th }}$ version) recommended low dose CS in a short time for deteriorating patient [40].

Thereafter, the use of CS, is still questionable, because of potential inhibition of viral clearance, increasing the duration of viremia and some evidence of disease progression. CS may be beneficial in the early acute phase of illness especially in low dose. Also, CS might serve as a bridge [74] to more specific antiviral therapies for covid-19. Although, its use in severe septic shock is doubtful, In HLH and hyper inflammatory storm may be more useful in an adequate point.

\section{Non-steroidal Anti-inflammatory Drugs (NSAID):}

NSAID as cyclooxygenase $(\operatorname{cox} 1 / \operatorname{cox} 2)$ inhibitors are used clinically for their anti-inflammatory, analgesic and anti-pyretic properties. COX1 provides PGs for housekeeping, while COX2 is up regulated at sites of inflammation by IL-1, TNF $\alpha$, endotoxins and growth factors [16].

Studies: Experience from in vitro studies for the use of NSAID, on COVID-19 is lacking. An in vitro study revealed that Ibuprofen and Naproxen, inhibited Ab production at pharmacologic doses [75]. A dramatic antiviral effect of Indomethacin was found in a model of feline coronavirus infected cells, also against Canine$\mathrm{CoV}$, by inhibiting virus replication and protecting the host cell from virus induced damage [76]. Also, one study [77] discussed on crucial mechanism of broad-spectrum anti-influenza virus activity of Naproxen including binding to nucleoproteins, both in vitro [78], and in vivo in animal model [79] assigned to nCoV. Antiviral efficacy of Indomethacin was determined by evaluating virus titers in CoV-infected dogs; also in one human study [80, 81]. Concerns about Ibuprofen seem to be from increasing an over expression of ACE2 in diabetic rats and diabetic patients $[82,83]$. So, this effect may worsen the clinical course and even susceptibility to COVID-19 infection theoretically [84]. Also, concerns about Ibuprofen invigorated from an unpublished idea of a French physician who indicated that four patients with COVID-19 after using NSAIDs developed severe illness [85]. Several studies suggest that the use of NSAIDs before or during admission with 
pneumonia including viral infection may be associated with an increased risk of empyema $[85,86]$.

A clinical review of chemotherapeutic strategy for severe COVID-19 pneumonia, pointed that Celecoxib and Thalidomide can modulates IкB $\alpha$ degradation and phosphorylation [87]. A team of King's College analyzed 89 existing studies cause by SARS viruses including SARS-CoV-2, and found no evidence for or against the use of NSAIDs [66].

Totally, till this moment the most comprehensive data is from analyzing of 89 existing studies. The researchers found no evidence for or against the use of NSAIDs in COVID-19 patients. While, we have more effective repositioning drugs, the use of NSAIDs is not rational.

\section{Thalidomide:}

This major teratogen agent has been used due to antiemetic, analgesic, anxiolytic and sedative properties or in template of some malignancies, autoimmune and infectious diseases [16]. It suppresses activated NF- $\mathrm{KB}$ that promote $\mathrm{TNF} \alpha$ production . Also, inhibits phagocytosis, chemotaxis, and reduces the expression of TNF $\alpha$, IL-1 $\beta$, and IL-6 mRNA $[16,88]$.

Studies: One study revealed that Thalidomide decreases the expression of IL-1 $\beta$ and IL-6 in human epithelial cells, so may helpful in preventing emphysema [89]. It can reduce the HIV replication by TNF $\alpha$ in human macrophages in vitro [90]. Moreover, it may express immunomodulatory effects in cell cultures, especially in combination with Celecoxib and suppress the production of TNF $\alpha$ and IL-8 via inhibition of NF-KB [87]. Anti-inflammatory effects of Thalidomide in an animal model showed that it decreased production of IL-1B, IL-6, TNF $\alpha$, and TGF $\beta$ [91]. It attenuates inflammation, oxidative stress and pulmonary fibrosis in mice lungs [92]. Also, Antifibrotic effects against bleomycin induced pulmonary fibrosis, were seen in rats [93]. In H1N1 influenza induced pulmonary injury in mice thalidomide dramatically inhibited the activated PNF-кB p6 and reduced the inflammation [94]. However, the beneficial effects of Thalidomide (100mg/day) in combination with low dose CS were shown in a 45 years old woman with COVID-19 [71].

Briefly, Thalidomide in addition to its ability to inhibit cytokine surge, and immunomodulation effects, could be helping the patients to reduce oxygen consumption, and relieve digestive symptoms in COVID-19 patients. So, may shed new light as a subsidiary treatment strategy. In combination with low dose CS, it clearly reduces the pulmonary symptoms and shorten the hospital stay. However, it is not able to deal with the very severe symptoms. Therefore, despite lack of strong evidence from large studies, we suggest it in the setting of treatment, from mild to severe cases in combination with other drugs, at this time.

\section{Intravenous Immunoglobulin (IVIG):}

IVIG is prepared from pooled human plasma. It administers mainly for autoimmune and auto inflammatory conditions and recently has been used as an anti-infectious agent [1, 95]. Its Fab mediated functions include suppression of cytokines, auto antibodies and complements, targeting of specific immune cell surface receptors, expression of Treg cells by induction of COX2 dependent PGE2 in Dendritic cells, and blockade of leukocyte adhesion molecule binding. Also some FC dependent activities include blockade of $\mathrm{Fc}-\gamma$ receptor $(\mathrm{Fc} \gamma \mathrm{R}), \mathrm{FcRn}$ and immunomodulation by salivated IgG $[95,96]$.

Studies: IVIG has been used as an anti-infectious in experimental models [97, 98]. Pyrc et al. showed that human sera form healthy people inhibited HCoV-NL63 infection. Moreover, they reported that IVIG can also neutralize H-CoV-NL63 [99]. In another study, IVIG that obtained from donors with higher Abs against RSV had significant potential to improve the outcome of RSV infection in immunocompromised subjects, not only by controlling viral replication, but also by reducing damage to lungs [100]. A murine model of induced colitis revealed that IVIG reduced intestinal inflammation by suppression of IL6, also inhibited growing of some microorganisms in the gut of mice [101]. In previous studies of SARS and MERS, IVIG has exhibited various clinical benefits $[102,103]$. The clinical data of 10 patients with COVID-19 receiving short term corticosteroid (160 mg/day) plus IVIG (20 gr/day) were conducted. This combination significantly reduced SpO2, lung lesions and normalized ALC and CRP levels [60]. Also administration of the high dose IVIG reported on 3 patients with COVID-19. It started just at the time of initiation of respiratory distress, with 
significant improvement in clinical symptoms and radiological findings [104]. Contrariwise, in one study with a total 416 COVID-19 patients that received CS and concurrent IVIG, the use of IVIG was not rescuer [61]. Zhang et al., described a couple that treated with methylprednisolone and IVIG successfully [70].

However, the efficacy of IVIG would be better if the immune IgG Abs will be specific against COVID-19 by boosting the immune response in newly infected patients, especially when it collected from patients recovered from COVID-19 in the same city or surrounding area [1].

IVIG seems to be golden drug in deteriorating patients, where it can be used at least as a bridge therapy. Patients might not receive much benefit when systemic damage has already taken place. It acts not only by controlling viral replication, but also by reducing damage to lungs.

\section{Cyclosporine (CsA):}

CsA has had a major impact on prevention of solid organ transplant rejection. Also, has potential effects for treatment of immunologically mediated diseases. CsA inhibits calcineurin, so inhibits the early phase of $\mathrm{T}$ cell activation and IL2-4, IL15 and INF $\gamma$ production, and may modulate anti-inflammatory effects by inhibiting of NF- $\mathrm{kB}[16]$.

Studies: Although Low micromolar, non-cytotoxic concentration of CsA strongly affected the replication of some viruses in cell culture, more concentration is need to block coronaviruses; suggesting that coronaviruses are less sensitive to CsA treatment [105]. CsA is considered as interaction partner of SARS-CoV N-protein [106]. It might exert its effect by inhibiting cyclophilin or even direct inhibitory effect on virus function [107]. It has been reported to inhibit the replication of HIV, vesicular stomatitis virus (VSV), HCV and influenza-A [108-111], but in vivo studies on CoVs family especially CoV-2 infection is required. The patients who fulfill the HLH criteria may benefit from the use of related chemotherapeutic agents like CsA [10,62].

We cannot suggest CsA as a first line therapeutic agent at this time, but it should be noted that it can be prescribe in HLH as a potentially effective drug.

\section{IL-6 blockers:}

Tocilizumab is a humanized monoclonal Ab to the soluble IL-6 receptor that can inhibit intracellular signaling that originates from IL-6. It administers in some auto-inflammatory and autoimmune diseases [95]. Since IL-6 and GM-CSF are key cytokines, which may result in lung injury [112], tocilizumab might be have therapeutic role for severe and critical COVID-19 [113].

Studies: The findings suggest that overexpression of IL- 6 and IL-2R are useful for estimating the severity of COVID-19 [114]. At least two animal models have been shown association between IL-6 level and SARS-CoV severity $[115,116]$. In contract, there was no significant difference in cytokine levels in the presence of SARS symptoms in 14 adult $\mathrm{CoV}$ patients [117]. This discrepancy has been justified in some studies with delayed inflammation [118], Imbalance between LI-6 and IL-10 [119] or the presence of another mechanism, such as gamma interferon related cytokine storm [120]. At least, it has been shown that 4 potential CoV therapeutic target (ADAM17, DUSP1, P38MAPK, GU-rich ssRNA) are related to IL-6 regulator [69,121,122]. In a review of 69 severe patients with COVID-19, the base line IL-6 was related to the maximal body temperature, CT findings and also related to the high base line levels of CRP, LDH, Ferritin and D-dimer. After treatment with drugs other than tocilizumab there was a marked decrease in IL-6 level and chest CT findings [123]. In another cohort, 21 patients with severe or critical criteria of $\mathrm{nCoV}$ pneumonia enrolled. All patients received tocilizumab (400 mg. once) in addition to routine therapies. Within a few days, all symptoms improved and high percentage of laboratory (including CRP, ALC) and CT scan findings decreased significantly. Finally, $19(90.5 \%)$ patients have been discharged on average 13.5 days after receiving tocilizumab [113]. A 65 years old male on a maintenance therapy for multiple myeloma admitted with severe COVID-19. He received tocilizumab and after 3 days chest tightness improved. Finally, Chest CT scan cleared after 10 days and discharged [124].

It is recommended that in patients with extensive lung lesions and severe illness with increased IL-6, 
tocilizumab can be administered for 1-2 dose [40].

Generally, the results are promising and tocilizumab has been used especially on severe and critical cases with beneficial effects. Because the peak level of IL-6 is associated with severity of pulmonary complications, tocilizumab can be used in this situation, where other drugs are ineffective. More studies are needed to determine that this target therapy has beneficial effects.

\section{IL-1 blockade:}

Anakinra is a human recombinant form of IL-1R $\alpha$. It prevents the interaction of the receptor with IL-1 and subsequent signaling. Thus, it uses in R.A, some auto-inflammatory disease (e.g., S.JIA, CAPS) and HLH [95]. The nCoV might be bind to TLRs which activate production of pro IL-1 that mediates the inflammation of lungs, fever and fibrosis [8].

Studies: Although one study showed no difference in IL-1 $\beta$ levels in patients with COVID-19 in any severity and general population [114], some others have been shown the beneficial effects of steroids in reducing IL-1 in SARS patients [53,125]. One animal model has been shown beneficial results for an IL-1 receptor antagonist in rat [126].

All patients with COVID-19 should be screened for hyper-inflammation, using laboratory tests and $\mathrm{H}$ score for needing to immunosuppressant like anakinra and tocilizumab [10,127].

Overall, large studies are need to evaluate the efficacy and safety of anakinra, as a target therapy. At this time, we suggest it, only in the situation of inflammatory storm that IL-6 is not high or in HLH /macrophage activation syndrome.

\section{JAK inhibitors:}

The therapeutic inhibition aspects of intracellular Janus kinase/ signal transducer and activator of transcription (JAK-STAT) pathway has yield promising results in many systemic, cancerous and cutaneous disease [95].

Studies: No published clinical trial evidence for JAK inhibitors as a treatment for COVID-19 is available at this time. But, one study suggested that baricitinib has potential beneficial effects to reducing both viral entry via receptor and also inflammation in COVID-19 [128]. A retrospective in vitro study using past SARS-COV and MERS-COV data reported that, baricitinib has shown no inhibitory activities against SARS-COV-2 at concentration of $3 \mu \mathrm{M}$ or $3.2 \mu \mathrm{M}$ [129]. The combination of sunitinib and erlotinib display potent activity against HCV, Dengue virus, Ebola virus [130]. Another class, the cellular tyrosine kinase inhibitors (e.g. imitinib), inhibited replication of MERS and SARS-CoVs in cellular culture cells and reduced overall mortality in a mouse model [131].

Although, these group historically can reduce viral infectivity, viral replication and the aberrant host inflammatory state; at this time no imperative conclusion can be made on efficacy and safety of them on COVID-19.

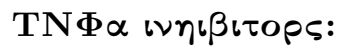

This group (e.g., Etanercept, Adalimumab) have been now proven in the treatment of some inflammatory and autoimmune conditions (e.g., RA, inflammatory bowel disease) [95].

Studies: These inhibitors produced a dramatic reduction of overall illness severity of virus-specific lung immunopathology in mice without interfering with viral clearance [132]. Etanercept has been reported to be effective for treatment of a non-infectious pulmonary syndrome like SARS pneumonia in one report [133]. A recent research letter suggested that, $\mathrm{TNF} \alpha$ blockade could have a potential role to reduce the lung damage during SARS-CoV infection [134]. In contrast, Etanercept alone was not sufficient to ameliorate disease in the virus-endotoxin mediated model of respiratory disease in pigs [135]. 
In conclusion, due to elevated TNF $\alpha$ in SARS- CoV, the use of TNF inhibitors, has a potential role to suppress the inflammatory cascade and ameliorating the severe alveolar damage. Also, these group can modulate biologic responses that are mediated by TNF or even induce immunosuppressive Treg cells (especially Adalimumab). Nevertheless, there is no evidence indicating that TNF $\alpha$ blockade is harmful in COVID-19 patients, and also there is not strong evidence for the use of them. Studies utilizing TNF $\alpha$ blocker for CoV-2 infection would be prudent.

\section{Conclusion}

Despite the collective wisdom, decision-making about treatment of COVID-19 especially in severe condition is challenging problem. Howbeit, several anti-inflammatory, immunomodulatory repositioning drugs have been candidate, their definite effects are unknown, and each one belongs to a time situation; where CS may be useful in the early acute phase of infection especially in low dose, and IVIG may help for all patients with moderate to severe disease just when their pulmonary symptoms begin. Because the peak level of IL-6 is associated with severity of pulmonary complications, tocilizumab can be used in severe and critical cases with beneficial effects, where other drugs are ineffective.

Unlike preliminary studies, HCQ was associated with an increased risk for escalation of respiratory support. Never the less, for ethical reasons and due to first results, alongside scatter experiences, the authors suggest using these drugs as therapeutic agents and even for prophylaxis especially in health workers. Also, thalidomide may shed new light on an adjutant treatment strategy for its potentially anti-viral effects. Therefore, despite lack of strong evidence from large studies, we suggest it in the setting of treatment, from moderate to severe cases in combination with other drugs. At this time, there is no evidence for or against the use of NSAIDs in COVID-19 patients. Using NSAIDs confronting to the virus function and replication does not logical when we have more effective and acceptable drugs. Also, we cannot suggest CsA as a first line therapeutic agent, but it should be noted that it can be prescribe in HLH as a potentially effective drug. Finally, large studies are need to evaluate the efficacy and safety of IL-1 and TNF $\alpha$ blockade as a target therapy. At this time, we suggest anakinra, only in the situation of inflammatory storm that IL-6 is not high or in HLH /macrophage activation syndrome. Although, JAK inhibitors, can reduce viral infectivity, viral replication and the aberrant host inflammatory state, historically; further in vitro and in vivo studies require to confirm their therapeutic effects.

Acknowledgments: The authors thank the staff and participants of this study for their important contributions.

\section{Conflicts of interest/Competing interests: None}

Funding information: Not applicable

\section{References}

1. Jawhara S. Could Intravenous Immunoglobulin Collected from Recovered Coronavirus Patients Protect against COVID-19 and Strengthen the Immune System of New Patients? International Journal of Molecular Sciences 2020; 21(7):2272.

2. Wu Z, McGoogan JM. Characteristics of and important lessons from the coronavirus disease 2019 (COVID-19) outbreak in China: summary of a report of 72314 cases from the Chinese Center for Disease Control and Prevention. JAMA 2020.

3. Wang D, Hu B, Hu C, Zhu F, Liu X, Zhang J, et al. Clinical characteristics of 138 hospitalized patients with 2019 novel coronavirus-infected pneumonia in Wuhan, China. JAMA 2020; 323(11):1061-9.

4. Wu JT, Leung K, Bushman M, Kishore N, Niehus R, de Salazar PM, et al. Estimating clinical severity of COVID-19 from the transmission dynamics in Wuhan, China. Nat Med 2020:1-5.

5. Hosseininasab A, Sinaei R, Bahman-Bijari B, Moeinaldini R. Nasal Colonization Rate of Community and Hospital Acquired Methicillin Resistant Staphylococcus Aureus in Hospitalized Children. Journal of Kerman University of Medical Sciences 2013; 20(1). 
6. Monteil V, Kwon H, Prado P, Hagelkrüys A, Wimmer RA, Stahl M, et al. Inhibition of SARS-CoV-2 infections in engineered human tissues using clinical-grade soluble human ACE2. Cell 2020.

7. Zhao J, He S, Minassian A, Li J, Feng P. Recent advances on viral manipulation of NF- $\varkappa$ B signaling pathway. Current opinion in virology 2015; 15:103-11.

8. Conti P, Ronconi G, Caraffa A, Gallenga C, Ross R, Frydas I, et al. Induction of pro-inflammatory cytokines (IL-1 and IL-6) and lung inflammation by Coronavirus-19 (COVI-19 or SARS-CoV-2): antiinflammatory strategies. J Biol Regul Homeost Agents 2020; 34(2).

9. Dong N, Yang X, Ye L, Chen K, Chan EW-C, Chen S. Genomic and protein structure modelling analysis depicts the origin and pathogenicity of $2019-\mathrm{nCoV}$, a new coronavirus which caused a pneumonia outbreak in Wuhan, China. F1000Research 2020; 9(121):121.

10. Mehta P, McAuley DF, Brown M, Sanchez E, Tattersall RS, Manson JJ. COVID-19: consider cytokine storm syndromes and immunosuppression. The Lancet 2020.

11. Ruan Q, Yang K, Wang W, Jiang L, Song J. Clinical predictors of mortality due to COVID-19 based on an analysis of data of 150 patients from Wuhan, China. Intensive Care Med 2020:1-3.

12. Rosa SGV, Santos WC. Clinical trials on drug repositioning for COVID-19 treatment. Rev Panam Salud Publica 2020; 44.

13. Favalli EG, Ingegnoli F, De Lucia O, Cincinelli G, Cimaz R, Caporali R. COVID-19 infection and rheumatoid arthritis: Faraway, so close! Autoimmunity reviews 2020:102523.

14. Monti S, Balduzzi S, Delvino P, Bellis E, Quadrelli VS, Montecucco C. Clinical course of COVID-19 in a series of patients with chronic arthritis treated with immunosuppressive targeted therapies. Ann Rheum Dis 2020.

15. Hassas Yeganeh M, Talaei M, Bazzaz AE, Rahmani K, Sinaei R, Fathi M, et al. Determination of diagnostic value (validity) leukocyte esterase (urine dipstick strip) in differentiating inflammatory arthritis from bacterial arthritis. Advances in Rheumatology 2020; 60(1):11.

16. Becker M, Lovell D, Leeder J. Chapter on Pharmacology. In: Petty R, Laxer R, Lindsley C, Wedderburn L, editors. Textbook of Pediatric Rheumatology 7ed2016.

17. Hassas Yeganeh M, Zafari N, Sardarinia M, Mahboubi L, Parvaneh VJ, Salehi S, et al. Autoimmune Hepatitis as an Initial Presentation of SLE. Archives of Pediatric Infectious Diseases 2016; 4(3).

18. Colson P, Rolain J-M, Raoult D. Chloroquine for the 2019 novel coronavirus. Int J Antimicrob Agents 2020.

19. Savarino A, Boelaert JR, Cassone A, Majori G, Cauda R. Effects of chloroquine on viral infections: an old drug against today's diseases. The Lancet infectious diseases 2003; 3(11):722-7.

20. Yan Y, Zou Z, Sun Y, Li X, Xu K-F, Wei Y, et al. Anti-malaria drug chloroquine is highly effective in treating avian influenza A H5N1 virus infection in an animal model. Cell Res 2013; 23(2):300-2.

21. Arya R, Das A, Prashar V, Kumar M. Potential inhibitors against papain-like protease of novel coronavirus (SARS-CoV-2) from FDA approved drugs. ChemrxivOrg 2020.

22. Wang M, Cao R, Zhang L, Yang X, Liu J, Xu M, et al. Remdesivir and chloroquine effectively inhibit the recently emerged novel coronavirus (2019-nCoV) in vitro. Cell Res 2020; 30(3):269-71.

23. Liu J, Cao R, Xu M, Wang X, Zhang H, Hu H, et al. Hydroxychloroquine, a less toxic derivative of chloroquine, is effective in inhibiting SARS-CoV-2 infection in vitro. Cell discovery 2020;6(1):1-4.

24. Yao X, Ye F, Zhang M, Cui C, Huang B, Niu P, et al. In vitro antiviral activity and projection of optimized dosing design of hydroxychloroquine for the treatment of severe acute respiratory syndrome coronavirus 2 (SARS-CoV-2). Clin Infect Dis 2020.

25. Gao J, Tian Z, Yang X. Breakthrough: Chloroquine phosphate has shown apparent efficacy in treatment of COVID-19 associated pneumonia in clinical studies. Bioscience trends 2020.

26. Chen Z, Hu J, Zhang Z, Jiang S, Han S, Yan D, et al. Efficacy of hydroxychloroquine in patients with COVID-19: results of a randomized clinical trial. MedRxiv 2020.

27. Gautret P, Lagier J-C, Parola P, Meddeb L, Mailhe M, Doudier B, et al. Hydroxychloroquine and azithromycin as a treatment of COVID-19: results of an open-label non-randomized clinical trial. Int J Antimicrob Agents 2020:105949.

28. Chen J, Liu D, Liu L, Liu P, Xu Q, Xia L, et al. A pilot study of hydroxychloroquine in treatment of 
patients with common coronavirus disease-19 (COVID-19). Journal of Zhejiang University (Medical Science) 2020; 49(1).

29. Sahraei Z, Shabani M, Shokouhi S, Saffaei A. Aminoquinolines against coronavirus disease 2019 (COVID-19): chloroquine or hydroxychloroquine. Int J Antimicrob Agents 2020:105945.

30. Barbosa J, Kaitis D, Freedman R, Le K, Lin X. Clinical outcomes of hydroxychloroquine in hospitalized patients with COVID-19: a quasi-randomized comparative study. N Engl J Med 2020.

31. Molina JM, Delaugerre C, Goff J, Mela-Lima B, Ponscarme D, Goldwirt L, et al. No evidence of rapid antiviral clearance or clinical benefit with the combination of hydroxychloroquine and azithromycin in patients with severe COVID-19 infection. Med Mal Infect 2020:30085-8.

32. Borba M, de Almeida Val F, Sampaio VS, Alexandre MA, Melo GC, Brito M, et al. Chloroquine diphosphate in two different dosages as adjunctive therapy of hospitalized patients with severe respiratory syndrome in the context of coronavirus (SARS-CoV-2) infection: Preliminary safety results of a randomized, double-blinded, phase IIb clinical trial (CloroCovid-19 Study). MedRxiv 2020.

33. Wang Y, Zhu L-Q. Pharmaceutical care recommendations for antiviral treatments in children with coronavirus disease 2019. World Journal of Pediatrics 2020:1-4.

34. Mingxing H. Expert consensus on chloroquine phosphate for the treatment of novel coronavirus pneumonia. Zhonghua Jie He He Hu Xi Za Zhi (Chinese J Tuberc Respir Dis) 2020; 43(3):185-8.

35. Chang R, Sun W-Z. Repositioning chloroquine as ideal antiviral prophylactic against COVID-19-time is now. 2020.

36. Kearney J. Chloroquine as a Potential Treatment and Prevention Measure for the 2019 Novel Coronavirus: A Review. 2020.

37. Zhou D, Dai S-M, Tong Q. COVID-19: a recommendation to examine the effect of hydroxychloroquine in preventing infection and progression. J Antimicrob Chemother 2020.

38. Colson P, Rolain J-M, Lagier J-C, Brouqui P, Raoult D. Chloroquine and hydroxychloroquine as available weapons to fight COVID-19. Int J Antimicrob Agents 2020; 105932(10.1016).

39. Dong L, Hu S, Gao J. Discovering drugs to treat coronavirus disease 2019 (COVID-19). Drug discoveries \& therapeutics 2020; 14(1):58-60.

40. Medicine NHCSAoTC. Diagnosis and Treatment Protocol for Novel Coronavirus Pneumonia (Trial Version 7). 2020.

41. Nicastri E, Petrosillo N, Bartoli TA, Lepore L, Mondi A, Palmieri F, et al. National Institute for the Infectious Diseases "L. Spallanzani", IRCCS. Recommendations for COVID-19 clinical management. Infectious Disease Reports 2020; 12(1).

42. Chan JF-W, Yao Y, Yeung M-L, Deng W, Bao L, Jia L, et al. Treatment with lopinavir/ritonavir or interferon- $\beta 1 \mathrm{~b}$ improves outcome of MERS-CoV infection in a nonhuman primate model of common marmoset. The Journal of infectious diseases 2015; 212(12):1904-13.

43. DeDiego ML, Nieto-Torres JL, Regla-Nava JA, Jimenez-Guardeño JM, Fernandez-Delgado R, Fett C, et al. Inhibition of NF- $x \mathrm{~B}-$ mediated inflammation in severe acute respiratory syndrome coronavirusinfected mice increases survival. J Virol 2014; 88(2):913-24.

44. Peiris JSM, Chu C-M, Cheng VC-C, Chan K, Hung I, Poon LL, et al. Clinical progression and viral load in a community outbreak of coronavirus-associated SARS pneumonia: a prospective study. The Lancet 2003; 361(9371):1767-72.

45. Lee N, Chan KA, Hui DS, Ng EK, Wu A, Chiu RW, et al. Effects of early corticosteroid treatment on plasma SARS-associated Coronavirus RNA concentrations in adult patients. J Clin Virol 2004; 31(4):304-9.

46. Arabi YM, Mandourah Y, Al-Hameed F, Sindi AA, Almekhlafi GA, Hussein MA, et al. Corticosteroid therapy for critically ill patients with Middle East respiratory syndrome. Am J Respir Crit Care Med 2018; 197(6):757-67.

47. Zhang X, Alekseev K, Jung K, Vlasova A, Hadya N, Saif LJ. Cytokine responses in porcine respiratory coronavirus-infected pigs treated with corticosteroids as a model for severe acute respiratory syndrome. J Virol 2008; 82(9):4420-8.

48. Xiao J, Ma L, Gao J, Yang Z, Xing X, Zhao H, et al. Glucocorticoid-induced diabetes in severe 
acute respiratory syndrome: the impact of high dosage and duration of methylprednisolone therapy. Zhonghua Nei Ke Za Zhi 2004; 43(3):179-82.

49. Lee DT, Wing Y, Leung HC, Sung JJ, Ng Y, Yiu G, et al. Factors associated with psychosis among patients with severe acute respiratory syndrome: a case-control study. Clin Infect Dis 2004; 39(8):12479.

50. Li Y, Wang S, Gao H, Wang J, Wei C, Chen L, et al. Factors of avascular necrosis of femoral head and osteoporosis in SARS patients' convalescence. Zhonghua Yi Xue Za Zhi 2004; 84(16):1348-53.

51. Lewis SR, Pritchard MW, Thomas CM, Smith AF. Pharmacological agents for adults with acute respiratory distress syndrome. Cochrane Database of Systematic Reviews 2019(7).

52. Zhao Z, Zhang F, Xu M, Huang K, Zhong W, Cai W, et al. Description and clinical treatment of an early outbreak of severe acute respiratory syndrome (SARS) in Guangzhou, PR China. J Med Microbiol 2003; 52(8):715-20.

53. Wong C, Lam C, Wu A, Ip W, Lee N, Chan I, et al. Plasma inflammatory cytokines and chemokines in severe acute respiratory syndrome. Clinical \& Experimental Immunology 2004; 136(1):95-103.

54. Chen R-c, Tang X-p, Tan S-y, Liang B-l, Wan Z-y, Fang J-q, et al. Treatment of severe acute respiratory syndrome with glucosteroids: the Guangzhou experience. Chest 2006; 129(6):1441-52.

55. Lansbury L, Rodrigo C, Leonardi-Bee J, Nguyen-Van-Tam J, Lim WS. Corticosteroids as adjunctive therapy in the treatment of influenza. Cochrane Database of Systematic Reviews 2019(2).

56. Jian-ya G. Clinical characteristics of 51 patients discharged from hospital with COVID-19 in Chongqing, China. MedRxiv 2020.

57. Qin X, Qiu S, Yuan Y, Zong Y, Tuo Z, Li J, et al. Clinical Characteristics and Treatment of Patients Infected with COVID-19 in Shishou, China. China (February 18, 2020). 2020.

58. Wang Y, Jiang W, He Q, Wang C, Wang B, Zhou P, et al. Early, low-dose and short-term application of corticosteroid treatment in patients with severe COVID-19 pneumonia: single-center experience from Wuhan, China. MedRxiv 2020.

59. Wu C, Chen X, Cai Y, Zhou X, Xu S, Huang H, et al. Risk factors associated with acute respiratory distress syndrome and death in patients with coronavirus disease 2019 pneumonia in Wuhan, China. JAMA internal medicine 2020.

60. Zhou Z-G, Xie S-M, Zhang J, Zheng F, Jiang D-X, Li K-Y, et al. Short-Term Moderate-Dose Corticosteroid Plus Immunoglobulin Effectively Reverses COVID-19 Patients Who Have Failed Low-Dose Therapy. 2020.

61. Shang J, Du R, Lu Q, Wu J, Xu S, Ke Z, et al. The treatment and outcomes of patients with COVID-19 in Hubei, China: a multi-centered, retrospective, observational study. 2020.

62. Huang C, Wang Y, Li X, Ren L, Zhao J, Hu Y, et al. Clinical features of patients infected with 2019 novel coronavirus in Wuhan, China. The Lancet 2020; 395(10223):497-506.

63. Chen N, Zhou M, Dong X, Qu J, Gong F, Han Y, et al. Epidemiological and clinical characteristics of 99 cases of 2019 novel coronavirus pneumonia in Wuhan, China: a descriptive study. The Lancet 2020; 395(10223):507-13.

64. Bhatraju PK, Ghassemieh BJ, Nichols M, Kim R, Jerome KR, Nalla AK, et al. Covid-19 in critically ill patients in the Seattle region - case series. NEJM 2020.

65. Zha L, Li S, Pan L, Tefsen B, Li Y, French N, et al. Corticosteroid treatment of patients with coronavirus disease 2019 (COVID-19). Med J Aust 2020.

66. Russell B, Moss C, George G, Santaolalla A, Cope A, Papa S, et al. Associations between immunesuppressive and stimulating drugs and novel COVID-19 - a systematic review of current evidence. ecancermedicalscience 2020; 14 .

67. Li G, Fan Y, Lai Y, Han T, Li Z, Zhou P, et al. Coronavirus infections and immune responses. J Med Virol 2020; 92(4):424-32.

68. Russell CD, Millar JE, Baillie JK. Clinical evidence does not support corticosteroid treatment for 2019-nCoV lung injury. The Lancet 2020; 395(10223):473-5.

69. Mahmud-Al-Rafat A, Majumder A, Rahman KT, Hasan AM, Islam KD, Taylor-Robinson AW, et al. Decoding the enigma of antiviral crisis: Does one target molecule regulate all? Cytokine 2019; 
115:13-23.

70. Zhang Z, Li X, Zhang W, Shi Z-L, Zheng Z, Wang T. Clinical features and treatment of 2019-nCov pneumonia patients in Wuhan: report of a couple cases. Virologica Sinica 2020:1-7.

71. Chen C, Qi F, Shi K, Li Y, Li J, Chen Y, et al. Thalidomide combined with low-dose glucocorticoid in the treatment of COVID-19 pneumonia. 2020.

72. Poston JT, Patel BK, Davis AM. Management of critically ill adults with COVID-19. JAMA 2020.

73. Alhazzani W, Møller MH, Arabi YM, Loeb M, Gong MN, Fan E, et al. Surviving Sepsis Campaign: guidelines on the management of critically ill adults with Coronavirus Disease 2019 (COVID-19). Intensive Care Med 2020:1-34.

74. Georgiev T. Coronavirus disease 2019 (COVID-19) and anti-rheumatic drugs. Rheumatol Int 2020; 40(5):825-6.

75. Bancos S, Bernard MP, Topham DJ, Phipps RP. Ibuprofen and other widely used non-steroidal antiinflammatory drugs inhibit antibody production in human cells. Cell Immunol 2009; 258(1):18-28.

76. Amici C, Di Coro A, Ciucci A, Chiappa L, Castilletti C, Martella V, et al. Indomethacin has a potent antiviral activity against SARS coronavirus. Antiviral therapy 2006; 11(8):1021.

77. Kickbusch I, Leung G. Response to the emerging novel coronavirus outbreak. BMJ Publishing Group 2020.

78. Lejal N, Tarus B, Bouguyon E, Chenavas S, Bertho N, Delmas B, et al. Structure-based discovery of the novel antiviral properties of naproxen against the nucleoprotein of influenza A virus. Antimicrob Agents Chemother 2013; 57(5):2231-42.

79. Zheng W, Fan W, Zhang S, Jiao P, Shang Y, Cui L, et al. Naproxen exhibits broad anti-influenza virus activity in mice by impeding viral nucleoprotein nuclear export. Cell reports 2019; 27(6):1875-85. e5.

80. Arai I, Mao G-P, Otani K, Konno S, Kikuchi S, Olmarker K. Indomethacin blocks the nucleus pulposusinduced effects on nerve root function. Eur Spine J 2004; 13(8):691-4.

81. Rane A, Oelz O, Frolich JC, Seyberth HW, Sweetman BJ, Watson JT, et al. Relation between plasma concentration of indomethacin and its effect on prostaglandin synthesis and platelet aggregation in man. Clinical Pharmacology \& Therapeutics 1978; 23(6):658-68.

82. Fu Y, Cheng Y, Wu Y. Understanding SARS-CoV-2-mediated inflammatory responses: from mechanisms to potential therapeutic tools. Virologica Sinica 2020:1-6.

83. Fang L, Karakiulakis G, Roth M. Are patients with hypertension and diabetes mellitus at increased risk for COVID-19 infection? The Lancet Respiratory Medicine 2020.

84. Day M. Covid-19: ibuprofen should not be used for managing symptoms, say doctors and scientists. BMJ Publishing Group 2020.

85. Kotsiou OS, Zarogiannis SG, Gourgoulianis KI. Prehospital NSAIDs use prolong hospitalization in patients with pleuro-pulmonary infection. Respir Med 2017; 123:28-33.

86. Le Bourgeois M, Ferroni A, Leruez-Ville M, Varon E, Thumerelle C, Brémont F, et al. Nonsteroidal anti-inflammatory drug without antibiotics for acute viral infection increases the empyema risk in children: a matched case-control study. The Journal of pediatrics 2016; 175:47-53. e3.

87. Masato H. Chemotherapeutic Strategy with Synbiotics, Thalidomide and Celecoxib for severe COVID19 Pneumonia. Association between microbiota, chronic inflammation and pneumonia2020.

88. Dastan F, Tabarsi P, Marjani M, Moniri A, Hashemian SM, Tavakoli-Ardakani M, et al. Thalidomide against Coronavirus Disease 2019 (COVID-19): A Medicine with a Thousand Faces. Iranian Journal of Pharmaceutical Research 2020:1-2.

89. Tabata C, Tabata R, Takahashi Y, Nakamura K, Nakano T. Thalidomide prevents cigarette smoke extract-induced lung damage in mice. International immunopharmacology 2015; 25(2):511-7.

90. Moreira AL, Corral LG, Ye W, Johnson B, Stirling D, Muller GW, et al. Thalidomide and thalidomide analogs reduce HIV type 1 replication in human macrophages in vitro. AIDS research and human retroviruses 1997; 13(10):857-63.

91. Amirshahrokhi K. Anti-inflammatory effect of thalidomide in paraquat-induced pulmonary injury in mice. International Immunopharmacology 2013; 17(2):210-5.

92. Dong X, Li X, Li M, Chen M, Fan Q, Wei W. Antiinflammation and antioxidant effects of thalidomide 
on pulmonary fibrosis in mice and human lung fibroblasts. Inflammation 2017; 40(6):1836-46.

93. Dong X, Li X, Li M, Chen M, Fan Q, Wei W. Inhibitory effects of thalidomide on bleomycin-induced pulmonary fibrosis in rats via regulation of thioredoxin reductase and inflammations. American journal of translational research 2017; 9(10):4390.

94. Zhu H, Shi X, Ju D, Huang H, Wei W, Dong X. Anti-inflammatory effect of thalidomide on H1N1 influenza virus-induced pulmonary injury in mice. Inflammation 2014; 37(6):2091-8.

95. Llowite NT, Laxer RM. Pharmacology: Biologics. In: Petty RE, Laxer RM, Lindsley CB, Wedderburn L, editors. Textbook of pediatric rheumatology. 7 ed: Elsevier Health Sciences 2015.

96. Trinath J, Hegde P, Sharma M, Maddur MS, Rabin M, Vallat J-M, et al. Intravenous immunoglobulin expands regulatory $\mathrm{T}$ cells via induction of cyclooxygenase-2-dependent prostaglandin $\mathrm{E} 2$ in human dendritic cells. Blood, the Journal of the American Society of Hematology 2013; 122(8):1419-27.

97. Hu D, Zhu C, Ai L, He T, Wang Y, Ye F, et al. Genomic characterization and infectivity of a novel SARS-like coronavirus in Chinese bats. Emerging microbes \& infections 2018; 7(1):1-10.

98. Ben-Nathan D, Lustig S, Tam G, Robinzon S, Segal S, Rager-Zisman B. Prophylactic and therapeutic efficacy of human intravenous immunoglobulin in treating West Nile virus infection in mice. The Journal of infectious diseases 2003; 188(1):5-12.

99. Pyrc K, Bosch BJ, Berkhout B, Jebbink MF, Dijkman R, Rottier P, et al. Inhibition of human coronavirus NL63 infection at early stages of the replication cycle. Antimicrob Agents Chemother 2006; 50(6):2000-8.

100. Boukhvalova M, Blanco J, Falsey A, Mond J. Treatment with novel RSV Ig RI-002 controls viral replication and reduces pulmonary damage in immunocompromised Sigmodon hispidus. Bone Marrow Transplant 2016; 51(1):119-26.

101. Charlet R, Sendid B, Kaveri SV, Poulain D, Bayry J, Jawhara S. Intravenous Immunoglobulin Therapy Eliminates Candida albicans and Maintains Intestinal Homeostasis in a Murine Model of Dextran Sulfate Sodium-Induced Colitis. International journal of molecular sciences 2019; 20(6):1473.

102. Wang J-T, Sheng W-H, Fang C-T, Chen Y-C, Wang J-L, Yu C-J, et al. Clinical manifestations, laboratory findings, and treatment outcomes of SARS patients. EID 2004; 10(5):818.

103. Arabi YM, Arifi AA, Balkhy HH, Najm H, Aldawood AS, Ghabashi A, et al. Clinical course and outcomes of critically ill patients with Middle East respiratory syndrome coronavirus infection. Ann Intern Med 2014; 160(6):389-97.

104. Cao W, Liu X, Bai T, Fan H, Hong K, Song H, et al., editors. High-dose intravenous immunoglobulin as a therapeutic option for deteriorating patients with Coronavirus Disease 2019. Open Forum Infectious Diseases; 2020: Oxford University Press US.

105. De Wilde AH, Zevenhoven-Dobbe JC, van der Meer Y, Thiel V, Narayanan K, Makino S, et al. Cyclosporin A inhibits the replication of diverse coronaviruses. J Gen Virol 2011; 92(Pt 11):2542.

106. Luo C, Luo H, Zheng S, Gui C, Yue L, Yu C, et al. Nucleocapsid protein of SARS coronavirus tightly binds to human cyclophilin A. Biochem Biophys Res Commun 2004; 321(3):557-65.

107. Te Velthuis AJ, Arnold JJ, Cameron CE, van den Worm SH, Snijder EJ. The RNA polymerase activity of SARS-coronavirus nsp12 is primer dependent. Nucleic Acids Res 2010; 38(1):203-14.

108. Briggs C, Ott D, Coren L, Oroszlan S, Tözsér J. Comparison of the effect of FK506 and cyclosporin A on virus production in H9 cells chronically and newly infected by HIV-1. Arch Virol 1999; 144(11):2151-60.

109. Bose S, Mathur M, Bates P, Joshi N, Banerjee AK. Requirement for cyclophilin A for the replication of vesicular stomatitis virus New Jersey serotype. J Gen Virol 2003; 84(7):1687-99.

110. Nakagawa M, Sakamoto N, Enomoto N, Tanabe Y, Kanazawa N, Koyama T, et al. Specific inhibition of hepatitis C virus replication by cyclosporin A. Biochem Biophys Res Commun 2004; 313(1):42-7.

111. Ma C, Li F, Musharrafieh RG, Wang J. Discovery of cyclosporine A and its analogs as broad-spectrum anti-influenza drugs with a high in vitro genetic barrier of drug resistance. Antiviral Res 2016; 133:6272.

112. Zhou Y, Fu B, Zheng X, Wang D, Zhao C, Qi Y, et al. Aberrant pathogenic GM-CSF+ T cells and inflammatory CD14+ CD16+ monocytes in severe pulmonary syndrome patients of a new coronavirus. bioRxiv 2020. 
113. Xu X, Han M, Li T, Sun W, Wang D, Fu B, et al. Effective treatment of severe COVID-19 patients with tocilizumab. ChinaXiv 2020; 202003(00026):V1.

114. Chen L, Liu H, Liu W, Liu J, Liu K, Shang J, et al. Analysis of clinical features of 29 patients with 2019 novel coronavirus pneumonia. Zhonghua jie he he hu xi za zhi= Zhonghua jiehe he huxi zazhi= Chinese journal of tuberculosis and respiratory diseases 2020; 43:E005-E.

115. Barnard DL, Day CW, Bailey K, Heiner M, Montgomery R, Lauridsen L, et al. Enhancement of the infectivity of SARS-CoV in BALB/c mice by IMP dehydrogenase inhibitors, including ribavirin. Antiviral Res 2006; 71(1):53-63.

116. Ishii K, Hasegawa H, Nagata N, Ami Y, Fukushi S, Taguchi F, et al. Neutralizing antibody against severe acute respiratory syndrome (SARS)-coronavirus spike is highly effective for the protection of mice in the murine SARS model. Microbiol Immunol 2009; 53(2):75-82.

117. Sheng W-H, Chiang B-L, Chang S-C, Ho H-N, Wang J-T, Chen Y-C, et al. Clinical manifestations and inflammatory cytokine responses in patients with severe acute respiratory syndrome. Journal of the Formosan Medical Association= Taiwan yi zhi 2005; 104(10):715-23.

118. Lau SK, Lau CC, Chan K-H, Li CP, Chen H, Jin D-Y, et al. Delayed induction of proinflammatory cytokines and suppression of innate antiviral response by the novel Middle East respiratory syndrome coronavirus: implications for pathogenesis and treatment. J Gen Virol 2013; 94(12):2679-90.

119. Lucena-Silva N, Torres LC, Luna CF, de Barros Correia J, da Silva GAP. The balance between the serum levels of IL- 6 and IL-10 cytokines discriminates mild and severe acute pneumonia. BMC pulmonary medicine 2016; 16(1):170.

120. Huang KJ, Su IJ, Theron M, Wu YC, Lai SK, Liu CC, et al. An interferon- $\gamma$-related cytokine storm in SARS patients. J Med Virol 2005; 75(2):185-94.

121. Li Y, Chen M, Cao H, Zhu Y, Zheng J, Zhou H. Extraordinary GU-rich single-strand RNA identified from SARS coronavirus contributes an excessive innate immune response. Microbes and infection 2013; 15(2):88-95.

122. Liao Y, Wang X, Huang M, Tam JP, Liu DX. Regulation of the p38 mitogen-activated protein kinase and dual-specificity phosphatase 1 feedback loop modulates the induction of interleukin 6 and 8 in cells infected with coronavirus infectious bronchitis virus. Virology 2011; 420(2):106-16.

123. Liu T, Zhang J, Yang Y, Zhang L, Ma H, Li Z, et al. The potential role of IL-6 in monitoring coronavirus disease 2019. Available at SSRN 3548761. 2020.

124. Zhang X, Song K, Tong F, Fei M, Guo H, Lu Z, et al. First case of COVID-19 in a patient with multiple myeloma successfully treated with tocilizumab. Blood advances 2020; 4(7):1307.

125. Zhang Y, Li J, Zhan Y, Wu L, Yu X, Zhang W, et al. Analysis of serum cytokines in patients with severe acute respiratory syndrome. Infect Immun 2004; 72(8):4410-5.

126. Miura TA, Wang J, Holmes KV, Mason RJ. Rat coronaviruses infect rat alveolar type I epithelial cells and induce expression of CXC chemokines. Virology 2007; 369(2):288-98.

127. Fardet L, Galicier L, Lambotte O, Marzac C, Aumont C, Chahwan D, et al. Development and validation of the HScore, a score for the diagnosis of reactive hemophagocytic syndrome. Arthritis \& Rheumatology 2014; 66(9):2613-20.

128. Richardson P, Griffin I, Tucker C, Smith D, Oechsle O, Phelan A, et al. Baricitinib as potential treatment for 2019-nCoV acute respiratory disease. Lancet (London, England) 2020; 395(10223):e30.

129. Ge Y, Tian T, Huang S, Wan F, Li J, Li S, et al. A data-driven drug repositioning framework discovered a potential therapeutic agent targeting COVID-19. Biorxiv 2020.

130. Bekerman E, Neveu G, Shulla A, Brannan J, Pu S-Y, Wang S, et al. Anticancer kinase inhibitors impair intracellular viral trafficking and exert broad-spectrum antiviral effects. J Clin Invest 2017; $127(4): 1338-52$.

131. Dyall J, Coleman CM, Hart BJ, Venkataraman T, Holbrook MR, Kindrachuk J, et al. Repurposing of clinically developed drugs for treatment of Middle East respiratory syndrome coronavirus infection. Antimicrob Agents Chemother 2014; 58(8):4885-93.

132. Hussell T, Pennycook A, Openshaw PJ. Inhibition of tumor necrosis factor reduces the severity of virus-specific lung immunopathology. Eur J Immunol 2001; 31(9):2566-73. 
133. Yanik G, Hellerstedt B, Custer J, Hutchinson R, Kwon D, Ferrara JL, et al. Etanercept (Enbrel) administration for idiopathic pneumonia syndrome after allogeneic hematopoietic stem cell transplantation. BB AND MT 2002; 8(7):395-400.

134. Tobinick E. TNF-[alpha] inhibition for potential therapeutic modulation of SARS coronavirus infection. Curr Med Res Opin 2004; 20(1):39.

135. Atanasova K, Van Gucht S, Van Reeth K. Anti-TNF- $\alpha$ therapy does not ameliorate disease in a model of acute virus-endotoxin mediated respiratory disease in pigs. Vet Immunol Immunopathol 2010; 137(12):12-9.

\section{Hosted file}

Tables . docx available at https://authorea. com/users/334145/articles/460210-anti-inflammatoryimmunomodulatory-agents-as-potential-strategies-against-covid-19-a-systematic-review 